\title{
A Comparison of Major Trauma Patient Transport Destination in Metropolitan Perth, Western
} Australia.

Miss Elizabeth Brown BSc (Hons) MSc ${ }^{1,2}$, elizabeth.e.brown@ postgrad.curtin.edu.au

Prehospital Resuscitation and Emergency Care Research Unit (PRECRU), School of Nursing, Midwifery, and Paramedicine, Curtin University, GPO Box U1987, Perth, WA 6845, Australia.

Dr Hideo Tohira PhD, MD, MEng, MPH, FJAAM ${ }^{1,3}$, hideo.tohira@ curtin.edu.au

Prehospital Resuscitation and Emergency Care Research Unit (PRECRU), School of Nursing, Midwifery, and Paramedicine, Curtin University, GPO Box U1987, Perth, WA 6845, Australia.

Associate Professor Paul Bailey MB BS, FACEM, PhD ${ }^{1,2,4}$, paul.bailey@ stjohnambulance.com.au Prehospital Resuscitation and Emergency Care Research Unit (PRECRU), School of Nursing, Midwifery, and Paramedicine, Curtin University, GPO Box U1987, Perth, WA 6845, Australia.

Professor Daniel Fatovich MB BS FACEM PhD ${ }^{1,4,5,6}$, Daniel.Fatovich@ @ealth.wa.gov.au Emergency Medicine, Royal Perth Hospital, University of Western Australia, Perth, 6000, Australia.

Dr Gavin Pereira PhD, MAppStats, BCM (Hons), GCRC 6, ${ }^{7,8}$. gavin.f.pereira@curtin.edu.au School of Public Health, Curtin University, Bentley, WA, 6102, Australia. Professor Judith Finn PhD, MEdSt, GradDipPH, BSc, DipAppSc, RN, RM, ICCert, FACN, FAHA 1,2, 3,89, judith.finn@ curtin.edu.au 
Prehospital Resuscitation and Emergency Care Research Unit (PRECRU), School of Nursing, Midwifery, and Paramedicine, Curtin University, GPO Box U1987, Perth, WA 6845, Australia.

\section{Affiliations}

${ }^{1}$ Prehospital Resuscitation and Emergency Care Research Unit (PRECRU), School of Nursing, Midwifery and Paramedicine, Curtin University, Bentley, WA, Australia.

${ }^{2}$ St John Ambulance Western Australia, Belmont, WA, Australia.

${ }^{3}$ Division of Emergency Medicine, The University of Western Australia.

${ }^{4}$ Emergency Medicine, Royal Perth Hospital, University of Western Australia.

${ }^{5}$ Centre for Clinical Research in Emergency Medicine, Harry Perkins Institute of Medical Research, WA, Australia

${ }^{6}$ School of Public Health, Curtin University, Bentley, WA, Australia.

${ }^{7}$ Telethon Kids Institute, WA, Australia

${ }^{8}$ School of Public Health and Preventive Medicine, Monash University, Melbourne, VIC, Australia

\section{Institution Addresses:}

Prehospital Resuscitation and Emergency Care Research Unit (PRECRU), School of Nursing, Midwifery, and Paramedicine, Curtin University, GPO Box U1987, Perth, WA 6845, Australia

St John Ambulance Western Australia, 209 Great Eastern Hwy, Belmont, Western Australia, 6104, Australia

\section{Corresponding author:}


Elizabeth Brown

Prehospital Resuscitation and Emergency Care Research Unit (PRECRU), School of Nursing, Midwifery, and Paramedicine, Curtin University, GPO Box U1987, Perth, WA 6845, Australia

Telephone: +61 892263327

Email: elizabeth.e.brown@postgrad.curtin.edu.au

Keywords: Emergency Medical Service, Trauma Centre, Prehospital Care, Major Trauma.

Running Title: Major Trauma Patient Transport Destination.

Word counts:

Total word count: 4,609 (including references, tables and figures)

Abstract: 250/250

\section{Competing interests}

Paul Bailey is the Medical Director for St John Western Australia (SJ-WA) and Judith Finn receives partial salary support from SJ-WA. Elizabeth Brown is an SJ-WA registered paramedic and $\mathrm{PhD}$ candidate and the recipient of a Scholarship funded by a National Health and Medical Research Council (NHMRC) Centre for Research Excellence grant.

\section{Funding}

This work was supported by the National Health and Medical Research Council (NHMRC) Centre for Research Excellence under grant, "Prehospital Emergency Care" (1116453). 


\section{What is known}

- As part of an optimal trauma system, prehospital triage should ensure transport of the right patient to the right hospital.

- Severely injured trauma patients should be treated at high-level Trauma Centres.

- Inaccurate prehospital triage results in patients who require Trauma Centre care not receiving this care or having access to this care delayed.

\section{What this paper adds}

- This study provides an overview of the characteristics and outcomes of major trauma patients by type of hospital destination.

- Those patients who were transported directly to the Trauma Centre were the youngest with the highest ISS.

- Those patients not receiving Trauma Centre care were older, had a higher proportion of major head injuries with falls as their mechanism of injury. 


\section{A Comparison of Major Trauma Patient Transport Destination in Metropolitan Perth, Western} Australia.

Background: Despite evidence of a lower risk of death, major trauma patients are not always transported to Trauma Centres. This study compares and examines the characteristics and outcomes of major trauma patients between transport destinations.

Methods: We undertook a retrospective cohort study of major trauma patients (Injury Severity Score $>15)$ transported by ambulance. Cases were divided into three transport destination groups: (1) Direct, those who were transported to the Trauma Centre directly from the scene; (2) Indirect, those who were transported to another hospital prior to Trauma Centre transfer and (3) Non-transfers, those who were transported to a non-Trauma Centre and never subsequently transferred. Median and interquartile range (IQR) were used to describe the groups and group differences were assessed using the Kruskal-Wallis test for continuous variables and Pearson chi-square for categorical variables.

Results: A total of 1,625 patients were included. The median age was oldest in the non-transfers cohort (72 years IQR 46-84). This group also had the highest proportion of falls from standing and major head injuries $(\mathrm{n}=298 / 400,75 \%, p<0.001)$. The non-transfers had the highest proportion of 30day mortality $(n=134 / 400,34 \%)$.

Conclusions: There were significant differences between the transport groups with older adults, falls and head injuries over-represented in the non-transfer group. Considering the ageing population, trauma systems will need to adapt.

Keywords: Emergency Medical Service, Trauma Centre, Prehospital Care, Major Trauma. 


\section{Background}

Major trauma patients are reported to have a significantly lower risk of death if their care is provided in a Trauma Centre ${ }^{1,2}$. In an optimal trauma system, prehospital triage ensures the transport of the right patient to the right hospital ${ }^{3}$. This system of care involves trauma patients being transported to a small number of specialised Trauma Centres, staffed and equipped to provide multidisciplinary care to severely injured patients, as opposed to the closest hospital facility. ${ }^{2,4,5}$ However, whether all major trauma patients should attend a Trauma Centre directly, bypassing closer lower level hospitals is a contentious issue and there is currently uncertainty as to whether direct transport reduces the risk of death ${ }^{6-8}$. Therefore, the decision as to where to transport major trauma patients is inherently complex and must consider the patients' physiological and anatomical injury severity, distance to the Trauma Centre and traffic conditions ${ }^{9}$.

The Western Australian (WA) Department of Health recommends that major trauma patients (defined as any injury that has the potential to cause prolonged disability or death) are transported directly to the Level 1 Trauma Centre ${ }^{10}$. The St John-WA (SJ-WA) Clinical Practice Guidelines highlight certain situations in which major trauma should be considered and direct transport to the Level 1 Trauma Centre initiated ${ }^{11}$. These include both mechanism of injury and anatomical criteria but exclude any physiological criteria. Mechanisms of injury include but are not limited to: motorbike crashes $>30 \mathrm{~km} / \mathrm{h}$ with injuries, motor vehicle crashes $>60 \mathrm{~km} / \mathrm{h}$ with injuries and falls from $>3$ metres. The anatomical criteria include amongst others: flail chest, pelvic fractures, open or depressed skull fractures and suspected spinal injuries ${ }^{11}$. If the patient has an imminent life-threat, paramedics are permitted to divert to the nearest Emergency Department for stabilisation ${ }^{11,12}$. The patient should then be prepared for rapid and early inter-hospital transfer to the Trauma Centre ${ }^{10}$. As the metropolitan area of Perth, WA spans more than $6000 \mathrm{~km}^{2}$ with the sole Level 1 Trauma Centre located in the centre of the city ${ }^{13}$ major trauma patients are not always transported to the Trauma Centre directly, with initial resuscitation and stabilisation often provided at a closer hospital facility prior to secondary transfer ${ }^{11,12}$. 
The aim of this study was to examine and compare the characteristics and outcomes of major trauma patients between transport destinations in the metropolitan area of Perth, WA. Transport destination was defined as being either direct or indirect transport to the Trauma Centre or non-transport to the Trauma Centre (i.e. those patients who died or were discharged from the initial hospital and not transferred to the Trauma Centre). We hypothesised that those not transported to the Trauma Centre would have different characteristics and outcomes from those transported directly and indirectly to the Trauma Centre. 


\section{Methods}

Study Design

We conducted a retrospective cohort study of patients aged $\geq 16$ years with major trauma, defined as an Injury Severity Score (ISS) >15 from a blunt or penetrating mechanism of injury, who were transported by SJ-WA in metropolitan Perth between $1^{\text {st }}$ January 2013 and $31^{\text {st }}$ of December 2016. Consistent with previous studies ${ }^{14,15}$ and the definition of physical trauma being 'a body wound produced by sudden physical injury from impact, violence or accident ${ }^{16}$, cases involving drowning, hanging or poisoning were excluded. Also excluded from the study were patients who were not transported (i.e. from the scene of the incident) by SJ-WA, patients not transported by road ambulance (i.e. helicopter or fixed-winged aircraft) and those with late effects of injury (more than 24-hours postinjury), or if their initial ambulance transport record could not be obtained.

\section{Study Setting}

SJ-WA is the sole provider of emergency ambulance services in WA, serving a population of over 2.5 million, with $78 \%$ of the state's population residing in the metropolitan area of Perth ${ }^{17}$. All metropolitan emergency ambulances are double-staffed with at least one qualified paramedic and all crews can provide advanced-life support, but not rapid sequence intubation ${ }^{11}$. Adult trauma patients who were transported during the study period would have attended one of nine hospitals: three tertiary and six secondary hospitals. One of the tertiary hospitals was the Level 1 Trauma Centre ${ }^{12}$. The other two tertiary hospitals provided services for limited inpatient management for a small number of major trauma patients upon agreement with the Level 1 Trauma Centre. The five secondary facilities and one private hospital provided definitive care for non-major trauma ${ }^{12}$.

\section{Data Sources}

Four hospitals contribute data to the State Trauma Registry. These include the three tertiary hospitals (including the Level 1 Trauma Centre) and one of the secondary hospitals. Included in the registry are data for patients transferred to one of these facilities after initial treatment at a metropolitan hospital 
that did not provide data to the registry ${ }^{18}$. Patients were identified in the State Trauma Registry if their ISS was $>15$, their mode of arrival was recorded as 'ambulance' and the location of where their injury occurred was depicted as 'metropolitan'.

Demographic details, injury mechanism, injury characteristics and discharge disposition (death, home, rehabilitation) were then extracted and linked with the ambulance transport record from the SJ-WA database using either deterministic or probabilistic matching (FRIL ver.2.1.5, Emory University and Centers for Disease Control and Prevention, Atlanta, Georgia, U.S.). Key identifiers (date of birth, first and last names and residential address) were used to create a likelihood score indicating a correct link between the databases. If the score was close to a predetermined cut-off value they were manually checked. Linkage failure occurred if the key identifiers were missing in the SJ-WA database.

Patient transport destination, prehospital observations and prehospital times were extracted from the SJ-WA database. This database contains information from the electronic patient care record (ePCR), completed for each case by paramedics, together with data from the computer-aided dispatch system. Cases were divided into three groups, based on transport destination: (1) Direct, those who were transported to the Trauma Centre directly from the scene of the incident. (2) Indirect, those patients who were transported to another metropolitan hospital prior to Trauma Centre transfer and (3) Nontransfers, those major trauma patients who were transported to one of the other three hospitals but never attended the Trauma Centre prior to death or discharge.

The cut-off values for the triage Revised Trauma Score informed categorisation of the physiological parameters as follows: a systolic blood pressure measurement $(\mathrm{SBP})<90 \mathrm{mmHg}$, a Glasgow Coma Scale Score (GCS) of $\leq 8$ and respiratory rate of $\leq 9$ or $>29$ on any prehospital recording ${ }^{19}$. A severity level of each injury was measured according to the Abbreviated Injury Scale (AIS) ranging from 6 (fatal) to 1 (minor). AIS codes were used to identify whether a patient sustained a major injury in the six ISS body regions (head/neck, face, chest, abdomen, extremities and external). We defined major injury as an injury with AIS $\geq 3$ and serious complications were defined as being acute kidney injury, acute myocardial infarction, acute respiratory distress syndrome, cardiac arrest, cardiac failure, deep 
vein thrombosis, pulmonary embolism, pneumonia, sepsis, stroke and unplanned return to the operating room ${ }^{20}$.

\section{Statistical Analysis}

It was anticipated that the data would be non-normally distributed, therefore, to describe the cohort we used median and interquartile range (IQR) for continuous variables and counts and percentages for categorical variables. Group differences were assessed using the Kruskal-Wallis test for continuous variables and Pearson chi-square or Fisher's exact for categorical variables. A $p$-value $<0.05$ was regarded as statistically significant. Data analysis was performed with IBM Statistical Package for Social Sciences (SPSS) Version 24.0 (IBM, Armonk, NY, USA).

\section{Ethics Approval}

Ethical approval was obtained from the Curtin University Human Research Ethics Committee (HR 128/2013). Ethics approval for access to the State Trauma Registry data was obtained from the Royal Perth Hospital Human Research Ethics Committee (PRN 464). Approval to access SJ-WA data was obtained from the SJ-WA Research Governance Committee.

\section{Results}

From the State Trauma Registry, we identified 1,904 major trauma cases occurring in the metropolitan area of Perth between $1^{\text {st }}$ January 2013 and $31^{\text {st }}$ of December 2016 of which 1,664 met the study inclusion criteria. Of these, the initial ambulance transport record for 34 cases could not be obtained. Three cases could not be linked, possibly due to inaccurate identifiers or incorrect recording of the mode of transport in the registry and two cases were duplicated in the registry (Figure 1). 
Of the 1,625 patients included in the study, $766(47 \%)$ were transported to the Trauma Centre directly, $459(28 \%)$ were transported indirectly to the Trauma Centre and 400 (25\%) were non-transfers (Table 1). The median age was oldest in the non-transfers cohort (72 years IQR $46-84$ versus 45 years IQR 27-64, direct and 49 IQR 29-72 indirect, $p=0.001)$. The non-transfers group had the highest proportion of falls from standing $(\mathrm{n}=212 / 400,53 \%, p<0.001)$ whereas the direct transport group had the highest proportion of motor vehicle crashes $(\mathrm{n}=152 / 766,20 \%, p<0.001)$ (Table 1). The indirect transport group had the lowest incidence of prehospital systolic blood pressure $<90 \mathrm{mmHg}(\mathrm{n}=45 / 459$, $p<0.001)$ respiratory rate of $<9$ or $>29(\mathrm{n}=41 / 459,9 \%, p<0.001)$ and a $\mathrm{GCS} \leq 8(\mathrm{n}=61 / 459,13 \%$, $p<0.001)$. Similarly, the indirect transport group had the lowest proportion of patients requiring prehospital cardiopulmonary resuscitation $(\mathrm{CPR})(\mathrm{n}=6,1.3 \%)$ whereas the non-transfers had the highest $(\mathrm{n}=43,10.8 \%, p<0.001)$ (Table 1). 
The median ISS was highest in the direct cohort (24 IQR 18-30 versus 22 IQR 17-26 indirect and non-transfers $p<0.001)$. Patterns of injuries were different between the study groups with the nontransfers having the highest proportion of major head injuries $(\mathrm{n}=298 / 400,75 \%, p<0.001)$ and the least chest and abdominal injuries (Table 2). There was a total of 333 deaths in 30-days with 154 $(46 \%)$ occurring in the direct group, $48(15 \%)$ in the indirect and $131(39 \%)$ in the non-transfer group $(p<0.001)$. Those in the non-transfer group had the highest proportion of 30-day mortality $(\mathrm{n}=131 / 400,33 \%)$. In the direct transport group the 30-day survivors had the longest LOS (10 days, IQR 5-21, $p<0.001)$ and there was the highest proportion of serious complications ( $\mathrm{n}=248,32 \%$, $p<0.001)$ (Table 2). 


\section{Discussion}

Our study found significant differences between major trauma patients who were transported directly or indirectly to the Trauma Centre by ambulance and those who never received Trauma Centre care, during the study period. The non-transfers group were older, with a higher proportion of head injuries and falls from standing as their mechanism of injury. The non-transfer group also had the highest proportion of prehospital CPR and death within 30-days. Those in the indirect group had the lowest incidence of prehospital CPR, death in the Emergency Department and death within 30-days and the direct group had the highest ISS and the lowest median age.

The triage of major trauma patients is a critical process in a trauma system and often relies on decision tools consisting of physiological, anatomical, mechanism of injury and special considerations criteria ${ }^{9}$. Transport destination decisions for major trauma patients are multifaceted, however, they are likely to be based on the need for immediate resuscitation, traffic conditions ${ }^{9}$ and geographic distance between the incident and the Trauma Centre ${ }^{21,22}$. The paramedics' decision not to take patients directly to the Trauma Centre is difficult to determine retrospectively and could be that the responsibility of single-handedly managing a critical patient prompted the paramedics to seek the closest Emergency Department or that the severity of the trauma was not initially identified.

Those in the indirect group had the smallest number of deaths compared to those in the direct and non-transfer groups. These patients also had the least evidence of prehospital physiological derangement suggesting that they were a more stable cohort ${ }^{7}$. It has recently been demonstrated that a 'trial of life' effect is present in severely injured blunt trauma patients who arrive at a Trauma Centre with vital signs, despite prolonged prehospital times and these patients have been found to have a substantially lower risk of subsequent mortality ${ }^{23}$. It is therefore plausible that there were fewer deaths in the indirect group as these patients had already undergone a trial of life and had less risk of mortality than those who were transported directly to the Trauma Centre and those who were never transported to the Trauma Centre. 
On inspection of the non-transfers group, it was found that these patients were older, with a higher percentage of head injuries and falls from standing as their mechanism of injury. These differences may have influenced the clinical decisions of the paramedics as to where to transport patients. For example, head injuries are more likely to require immediate airway interventions, thus making transport to the nearest hospital more likely ${ }^{24}$. Conversely, it has been shown that older adults with severe injuries are less likely to be transported to a Trauma Centre than younger adults ${ }^{25,26}$. Reasons for this include the ability of older adults to appear deceptively uninjured due to their lack of apparent physiological derangement ${ }^{27,28}$ and presence of occult hypoperfusion, which is difficult to identify ${ }^{29}$. Furthermore, there is often the presence of comorbidities, polypharmacy, anticoagulation/antiplatelet therapies and physiologic changes that can alter the response to injury ${ }^{29}$. Concerningly, the undertriaging of older adults increases the odds of mortality ${ }^{26,28}$.

Major trauma is often associated with injuries that result in gross anatomical disruption or external haemorrhage which are easily recognised ${ }^{30}$. This may account for the higher proportion of patients injured in high energy transfer mechanisms of injury, such as motor vehicle crashes and the higher median ISS in the direct group. It is important to highlight that an ISS $>15$ is a retrospective diagnosis which is made using information such as imaging, that is not available prehospital ${ }^{31}$. The current SJWA Major Trauma Guideline does not include a fall $<3$ metres as a consideration for Level 1 Trauma Centre transport. Therefore, for a patient of any age with a fall from standing to be recognised as potentially having major trauma they would have to meet one of the anatomical criteria in the SJ-WA Major Trauma Guideline. Closed head injuries, which are highly prevalent in older adults because of increased use of anticoagulation and antiplatelet therapy ${ }^{32}$, are not listed as an anatomical criterion. It is, therefore, unlikely that a patient with a fall from standing and a concomitant closed head injury would be considered for Trauma Centre transport and this, therefore, may account for the high proportion of falls in the non-transfer group.

The reasons for these patients in the non-transfer group not subsequently being transferred to the Trauma Centre are not understood. It is possible that the decision not to transfer may have been influenced by the patient's instability or the perception that the transfer would be futile due to pre- 
existing comorbidities or functional status. Furthermore, death may have occurred prior to transfer ${ }^{33}$ or a decision made on end of life care.

Major trauma has traditionally been viewed as a disease of the young ${ }^{33}$. However, in Australia, an increase in the proportion of major trauma patients aged $\geq 65$ has been observed ${ }^{34}$ and we have previously demonstrated that in the metropolitan area of Perth the median age of those with major trauma is 51 years of age and the most common mechanism of injury is a fall from standing ${ }^{31}$. Although mortality in older adults is known to be higher than their younger counterparts ${ }^{35}$, it has been suggested that with appropriately configured services, good outcomes can be achieved ${ }^{36}$. Given this shift in major trauma to a greater proportion of older adults, trauma systems need to adapt to these changes ${ }^{33}$. Developing ways in which to identify major trauma in older patients prehospital is essential to enable these patients to receive appropriate care. It has previously been shown that the adoption of specific prehospital trauma triage criteria can significantly improve the detection of older patients requiring specialised care ${ }^{37}$. However, this will need to occur without reducing triage specificity. Further to this, training should be provided to paramedics regarding the altered response to trauma in older adults, which may assist in ensuring appropriate care for these patients ${ }^{25}$. In light of our findings, we suggest that there may be benefit in the addition of older adults as a special population in the Major Trauma Guideline.

\section{Limitations}

Our study has the following potential limitations. Data regarding the decision making of the paramedics were not available. Therefore, it is not known whether the patient's initial transport destination was the Trauma Centre but diversion to a closer hospital for stabilisation from imminent life threats was required.

As with all studies using retrospective trauma registry data, the studies are subject to potential survivor bias. Patients who exclusively attended a hospital that did not provide data to the State Trauma Registry were not featured in the registry and these patients may have had different outcomes and characteristics from those included in the study. 


\section{Conclusion}

We found significant differences between major trauma patients transported directly or indirectly to the Trauma Centre and those who were never transported to the Trauma Centre prior to death or discharge; with older adults, falls and head injuries over-represented in the non-transfer group. Considering the ageing population, trauma systems will need to adapt to these changes. 


\section{Acknowledgements}

The authors are grateful for the support of State Trauma Programme Manager and thank SJ-WA for their support of our study.

\section{Disclosure}

This work was supported by the National Health and Medical Research Council (NHMRC) Centre for Research Excellence under grant, "Prehospital Emergency Care" (1116453).

\section{References}

1. MacKenzie EJ, Rivara FP, Jurkovich GJ, Nathens AB, Frey KP, Egleston BL, et al. A national evaluation of the effect of trauma-center care on mortality. N Engl J Med. 2006;354(4):366-78.

2. Curtis K, Chong S, Mitchell R, Newcombe M, Black D, Langcake M. Outcomes of severely injured adult trauma patients in an Australian health service: Does trauma center level make a difference? World J Surg. 2011;35(10): 2332-40.

3. van Rein E, van der Sluijs R, Houwert R, Gunning A, Lichtveld R, Leenen L, et al. Effectiveness of prehospital trauma triage systems in selecting severely injured patients: Is comparative analysis possible? Am J Emerg Med. 2018;36(6):1060-9.

4. Gabbe BJ, Simpson PM, Sutherland A, Wolfe R, Fitzgerald MC, Judson R, et al. Improved functional outcomes for major trauma patients in a regionalized, inclusive trauma system. Ann Surg. 2012;255(6):1009-15.

5. Dinh M, Curtis K, Mitchell R, Bein K, Balogh Z, Seppelt I, et al. Major trauma mortality in rural and metropolitan NSW, 2009-2014: A retrospective analysis of trauma registry data. Med J Aust. 2016;205(9):403-7.

6. Mans S, Reinders Folmer E, de Jongh MA, Lansink KW. Direct transport versus inter hospital transfer of severely injured trauma patients. Injury. 2016;47(1):26-31. 
7. Hill AD, Fowler RA, Nathens AB. Impact of interhospital transfer on outcomes for trauma patients: A systematic review. J Trauma. 2011;71(6):1885-9000.

8. Williams T, Finn J, Fatovich D, Jacobs I. Outcomes of different health care contexts for direct transport to a trauma center versus initial secondary center care: A systematic review and meta-analysis. Prehosp Emerg Care. 2013;17(4):442-57.

9. Brown J, Sajankila N, Claridge JA. Prehospital assessment of trauma. Surg Clin North Am. 2017;97(5):961-83.

10. Government of Western Australia East Metropolitan Health Service. Guiding principles for major trauma inter hospital transfer. Available from:

www.health.wa.gov.au/trauma system and services/home/trauma.guidelines.com. Accessed August 25, 2018.

11. St John Western Australia. Clinical Practice Guidelines for ambulance care in Western Australia - Paramedic, Industrial Paramedic, Ambulance Officer, Ambulance Transport Officer - Version 31. Clinical Practice Guidelines. Belmont, Western Australia, 6104

12. Towler S. trauma system and services - report of the trauma working group. Western australia: Delivering a healthy wa, 2007. Western Australia: Delivering a Healthy WA; 2007. Available from: http://www.health.wa.gov.au/trauma system and services/home/about.cfm Accessed August 25, 2018.

13. Australian Bureau of Statistics. 2071.0 - Census of population and housing: Reflecting Australia - stories from the census, 2016. Available from: http://www.abs.gov.au/ausstats/abs@.nsf/Lookup/by\%20Subject/2071.0 2016 Main\%20Feat ures Ageing\%20Population 14. Accessed August 25, 2018.

14. McCoy CE, Menchine M, Sampson S, Anderson C, Kahn C. Emergency medical services out-of-hospital scene and transport times and their association with mortality in trauma patients presenting to an urban level I trauma center. Ann Emerg Med 2013;61(2):167-74.

15. Beck B, Bray JE, Cameron P, Straney L, Andrew E, Bernard S, et al. Predicting outcomes in traumatic out-of-hospital cardiac arrest: The relevance of Utstein factors. Emerg Med J. 
16. Department of Health. Healthy Western Australia - ealth information for Western Australians - trauma. Available from: http://healthywa.wa.gov.au/Articles/S_T/Trauma. Accessed June $15,2019$.

17. Australian Bureau of Statistics. 3101.0 - Australian demographic statistics, 2016. Available from: http://www.abs.gov.au/ausstats/abs@.nsf/mf/3101.0. Accessed August 25, 2018.

18. Western Australian Department of Health. Western Australian State Trauma Registry. 2017. Available from: http://ww2.health.wa.gov.au/Articles/U_Z/WA-State-Trauma-Registry. Accessed June15, June 2019.

19. Champion HR, Sacco WJ, Copes WS, Gann DS, Gennarelli TA, Flanagan ME. A revision of the trauma score. J Trauma. 1989;29(5):623-9.

20. Hemmila MR, Cain-Nielsen AH, Wahl WL, Vander Kolk WE, Jakubus JL, Mikhail JN, et al. Regional collaborative quality improvement for trauma reduces complications and costs. J Trauma Acute Care Surg. 2015;78(1):78-87.

21. Garwe T, Stewart K, Stoner J, Newgard CD, Scott M, Ying Z, et al. Out-of-hospital and interhospital under-triage to designated tertiary trauma centers among injured older adults: A 10year statewide geospatial-adjusted analysis. Prehosp Emerg Care. 2017;21(6):734-43.

22. Newgard CD, Fu R, Bulger E, Hedges JR, Mann NC, Wright DA, et al. Evaluation of rural vs urban trauma patients served by 9-1-1 emergency medical services. JAMA Surg. 2017;152(1):11-8.

23. Clements TW, Vogt K, Hameed SM, Parry N, Kirkpatrick AW, Grondin SC, et al. Does increased prehospital time lead to a "trial of life" effect for patients with blunt trauma? J Surg Res. 2017;216:103-8.

24. Fatovich DM, Phillips M, Jacobs IG. A comparison of major trauma patients transported to trauma centres vs. Non-trauma centres in metropolitan Perth. Resuscitation. 2011;82(5):5603.

25. Chang DC, Bass RR, Cornwell EE, Mackenzie EJ. Undertriage of elderly trauma patients to state-designated trauma centers. Arch Surg. 2008;143(8):776-81. 
26. Brown E, Tohira H, Bailey P, Fatovich D, Pereira G, Finn J. Older age is associated with a reduced likelihood of ambulance transport to a trauma centre after major trauma in Perth. Emerg Med Australas. 2019.

27. Fatovich DM, Burrell M, Jacobs IG. Major trauma deaths at Perth secondary hospitals. Emerg Med Australas. 2011;23(6):754-60.

28. Rogers A, Rogers F, Bradburn E, Krasne M, Lee J, Wu D, et al. Old and undertriaged: A lethal combination. Am Surg. 2012;78(6):711-5.

29. Nakamura Y, Daya M, Bulger EM, Schreiber M, Mackersie R, Hsia RY, et al. Evaluating age in the field triage of injured persons. Ann Emerg Med. 2012;60(3):335-45.

30. Scheetz LJ. Prehospital factors associated with severe injury in older adults. Injury. 2010;41(9):886-93.

31. Brown E Tohira H, Bailey P, Fatovich D, Finn J. Major trauma patients are not who you might think they are. A linked data study. Australasian Journal of Paramedicine. 2019

32. Franko J, Kish KJ, O'Connell BG, Subramanian S, Yuschak JV. Advanced age and preinjury warfarin anticoagulation increase the risk of mortality after head trauma. J Trauma. 2006;61(1):107-10.

33. Beck B, Cameron P, Lowthian J, Fitzgerald M, Judson R, Gabbe BJ. Major trauma in older persons. BJS Open. 2018;2(5):310-8.

34. Dinh MM, Roncal S, Byrne CM, Petchell J. Growing trend in older patients with severe injuries: Mortality and mechanisms of injury between 1991 and 2010 at an inner city major trauma centre. ANZ J Surg. 2013;83(1-2):65-9.

35. Ayoung-Chee P, McIntyre L, Ebel BE, Mack CD, McCormick W, Maier RV. Long-term outcomes of ground-level falls in the elderly. J Trauma Acute Care Surg. 2014;76(2):498503; discussion

36. Lau D, El-Sayed AM, Ziewacz JE, Jayachandran P, Huq FS, Zamora-Berridi GJ, et al. Postoperative outcomes following closed head injury and craniotomy for evacuation of hematoma in patients older than 80 years. J Neurosurg. 2012;116(1):234-45. 
37. Ichwan B, Darbha S, Shah MN, Thompson L, Evans DC, Boulger CT, et al. Geriatric-specific triage criteria are more sensitive than standard adult criteria in identifying need for trauma center care in injured older adults. Ann Emerg Med. 2015;65(1):92-100.

38. Brown E, Tohira H, Bailey P, Fatovich D, Pereira G, Finn J. Longer prehospital time was not associated with mortality in major trauma. A retrospective cohort study. Prehosp Emerg Care. 2018;23(4):527-537.

Table 1. Demographic, mechanism of injury and physiologic data comparing major trauma patients transported by SJ-WA directly or indirectly to the Trauma Centre and non-transfers.

$\begin{array}{lll}\text { Median (IQR) } & \text { Median (IQR) } & \text { Median (IQR) } \\ \text { or count (\%) } & \text { or count (\%) } & \text { or count (\%) }\end{array}$

\begin{tabular}{llll}
\hline Total & $766(47)$ & $459(28)$ & $400(25)$
\end{tabular}

\section{Patient Demographics}

Age

Male Sex
49 (29-72)

$329(71.7)$
$72(46-84)$

$240(60)$

$<0.001 *$

\section{Mechanism}

MVC

$152(20)$

$81(18)$

$26(7)$

MBC

$116(15)$

67 (15)

$34(9)$ 


\begin{tabular}{|c|c|c|c|}
\hline Pedestrian & $73(10)$ & $21(5)$ & $12(3)$ \\
\hline Pedal Cyclist & $38(5)$ & $19(4)$ & $12(3)$ \\
\hline Fall from Height & $113(15)$ & $61(13)$ & $48(12)$ \\
\hline Falls from Standing & $112(15)$ & $136(30)$ & $212(53)$ \\
\hline Violence (gunshot, stabbing, & $86(11)$ & $44(10)$ & $29(7)$ \\
\hline assault) & & & \\
\hline Other (fire, sport related, other) & $76(10)$ & $30(7)$ & $27(7)$ \\
\hline
\end{tabular}

\section{Prehospital Characteristics}

Prehospital CPR

$53(6.9)$

$6(1.3)$

$43(10.8)$

$<0.001 *$

\section{Prehospital Observations}

SBP $<90 \mathrm{mmHg}$

Respiratory Rate $\leq 9$ or $>29$

GCS $\leq 8$

Prehospital Time $^{a}$
$189(25)$

$156(20)$

209 (27)

$55(44-69)$
45 (10)

$41(9)$

$61(13)$
$78(20)$

$59(15)$

$80(20)$
$<0.001 *$

$<0.001^{*}$

$<0.001 *$

Total Pre-Hospital Time (IQR)

$51(40-65)$

$53(42-63)$

$0.001 *$

Data analysed with Kruskal-Wallis test for continuous variables and Pearson chi-squared or Fisher's exact for categorical variables. Presented as median (IQR-interquartile range) or count (percentage) Time variables are presented in minutes. ${ }^{*}$ Significant ${ }^{\text {a }}$ Time from the emergency call being received to the patient's arrival at hospital. Abbreviations: $C P R=$ Cardiopulmonary Resuscitation, GCS=Glasgow Coma Scale score, $M B C=$ Motorbike crash, $M V C=$ Motor vehicle crash, SBP = systolic blood pressure. 
Table 2. Injury characteristics and outcomes data comparing major trauma patients transported by SJ-

WA directly or indirectly to the Trauma Centre and non-transfers.

\begin{tabular}{|c|c|c|c|c|}
\hline & Direct & Indirect & Non-Transfers & $p$-value \\
\hline & Median (IQR) & Median (IQR) & Median (IQR) & \\
\hline & or count $(\%)$ & or count $(\%)$ & or count $(\%)$ & \\
\hline Total & $766(47)$ & $459(28)$ & $400(25)$ & \\
\hline \multicolumn{5}{|c|}{ Trauma Characteristics } \\
\hline Injury Severity Score & $24(18-30)$ & $22(17-26)$ & $22(17-26)$ & $<0.001 *$ \\
\hline Blunt Trauma & 725 (94.6) & $449(97.8)$ & $390(97.5)$ & $0.006^{*}$ \\
\hline
\end{tabular}

\begin{tabular}{|c|c|c|c|c|}
\hline Major Injury & & & & \\
\hline Head/Neck & 453 (59) & $330(72)$ & $298(75)$ & $<0.001 *$ \\
\hline Face $^{a}$ & $11(1)$ & $5(1)$ & $2(1)$ & 0.359 \\
\hline Chest & $329(43)$ & $166(36)$ & $110(28)$ & $<0.001 *$ \\
\hline Abdomen & $128(17)$ & $69(15)$ & $46(12)$ & 0.060 \\
\hline Extremities & $179(23)$ & $59(13)$ & $43(11)$ & $<0.001 *$ \\
\hline External $^{\mathrm{a}}$ & $31(4)$ & $2(0.4)$ & $10(3)$ & $0.001 *$ \\
\hline
\end{tabular}




\section{Mortality Outcomes}

Death in 30-days

Died in Emergency

Department
$154(20)$

$54(7.0)$

$4(0.9)$

$48(10)$

$131(33)$

$<0.001 *$

$47(11.8)$

$<0.001^{*}$

\section{Outcomes}

Survivor Length of Stay

Any Serious Complication
$10(5-21)$

248 (32)
$8(5-14)$

109 (24)
$8(3-15)$

$50(13)$
$<0.001 *$

$<0.001^{*}$

Data analysed with Kruskal-Wallis test for continuous variables and Pearson chi-squared or Fisher's exact for categorical variables. presented as median (IQR-interquartile range) or count (percentage) Time variables are presented in minutes. ${ }^{*}$ Significant ${ }^{\text {a }}$ Fishers Exact Test. Major Injury AIS $\geq 3$. 
Figure 1. Flowchart of included and excluded patients. ${ }^{38}$

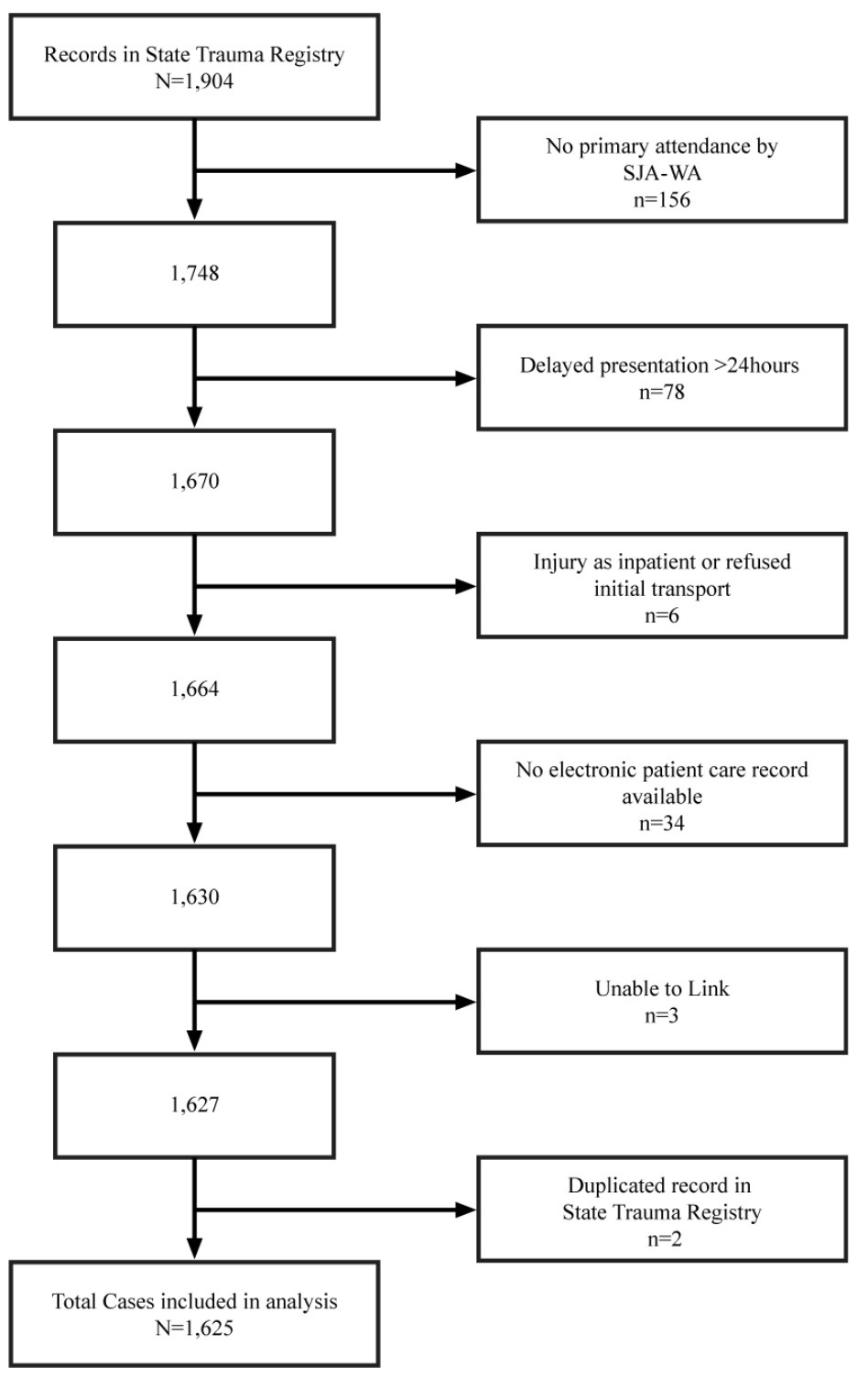

Permission to reproduce figure gained from Prehospital Emergency Care ${ }^{38}$. 